PNL-2803

UC-20d

\title{
Factors Affecting Potential \\ Market Penetration of Laser \\ Fusion Power Plants
}
D. E. Deonigi
D. W. Fraley

August 1979

Prepared for the U.S. Department of Energy under Contract EY-76-C-06-1830

Pacific Northwest Laboratory

Operated for the U.S. Department of Energy by Battelle Memorial Institute 


\title{
NOTICE
}

This report was prepared as an account of work sponsored by the United States Government. Neither the United States nor the Department of Energy, nor any of their employees, nor any of their contractors, subcontractors, or their employees, makes any warranty, express or implied, or assumes any legal liability or responsibility for the accuracy, completeness or usefulness of any information, apparatus, product or process disclosed, or represents that its use would not infringe privately owned rights.

The views, opinions and conclusions contained in this report are those of the contractor and do not necessarily represent those of the United States Government or the United States Department of Energy.

\author{
PACIFIC NORTHWEST LABORATORY \\ operated by \\ BATTELLE \\ for the \\ UNITED STATES DEPARTMENT OF ENERGY \\ Under Contract EY-76-C-06-1830
}
Printed in the United States of America
Available from
National Technical information Service
United States Department of Commerce
5285 Port Royal Road
Springfieid, Virginia 22151

Price: Printed Copy $5 \_$_ : Microfiche $\$ 3.00$

NTIS

-Pages Selling Price

$001-025 \quad \$ 4.00$

$026-050 \quad \$ 4.50$

$051-075 \quad \$ 5.25$

076-100 $\quad \$ 6.00$

$101-125 \quad \$ 6.50$

$126-150 \quad 57.25$

$151-175 \quad 58.00$

$176-200 \quad 59.00$

$201-225 \quad \$ 9.25$

$226.250 \quad 59.50$

$251-275 \quad 510.75$

$276-300 \quad \$ 11.00$ 
D. E. Deonigi

D. W. Fraley

August 1979

Prepared for

the U.S. Department of Energy under Contract EY-76-C-06-1830

Pacific Northwest Laboratory

Richland, WA 99352 


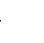




\section{EXECUTIVE SUMMARY}

A mini-model has been constructed to estimate the optimal size of laser fusion power plants and to estimate the allowable cost of the first such plant in relation to the next best alternative. In estimating the costs of laser fusion, the mini-model incorporates such factors as market penetration, learning, economies of scale, system size, transmission costs, reserve requirements, development and licensing costs and site costs.

The results of the mini-model simulations indicate that the optimal laser fusion plant size is approximately 3 GWe; risk considerations unincorporated in the mini-model suggest an optimal size closer to 2.5 GWe. This is in contrast to the findings of others which indicate the optimal size to be up to $10 \mathrm{GWe}$. The results indicate that the allowable cost of the first laser fusion plant is approximately 1.5 to 2 times that of the next best alternative. The results also indicate that the total debt accumulated during introduction ranges from $\$ 0.8$ to $\$ 2.1$ billion 1978 dollars. This debt could be considered as the maximum amount of subsidy needed from society for the construction of the first four fusion plants. 
• 


\section{CONTENTS}

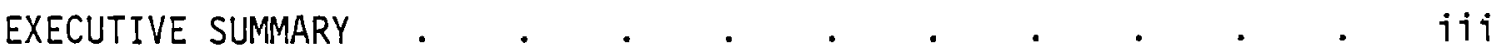

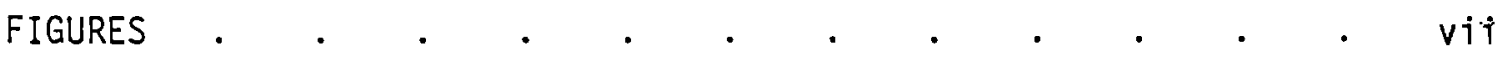

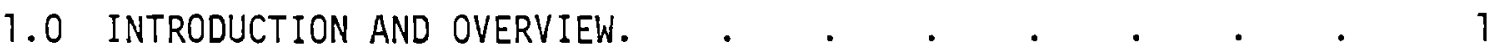

MINI-MODEL OVERVIEW: A COMPARISON OF COSTS $. \quad \cdot \quad \cdot \quad . \quad 1$

2.0 FACTORS AFFECTING THE COSTS OF LASER FUSION PLANTS TO

SOCIETY $. \quad . \quad . \quad . \quad . \quad . \quad . \quad . \quad . \quad . \quad . \quad 5$

MARKET PENETRATION OF LASER FUSION TECHNOLOGY. . . . $\quad$. 5

LENGTH OF CONSTRUCTION PERIOD . . . . . . . . . 7

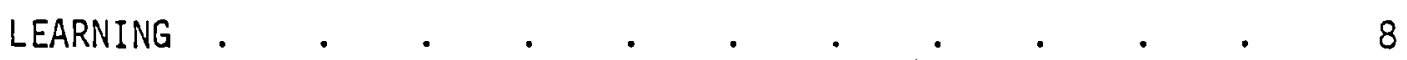

SCALE ECONOMIES.

THE SIZE OF THE UTILITY'S SYSTEM .

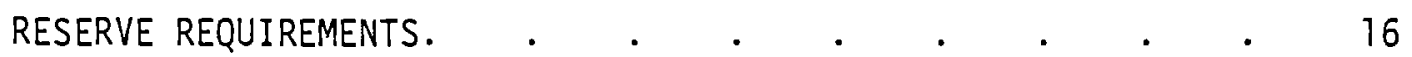

TRANSMISSION COSTS .

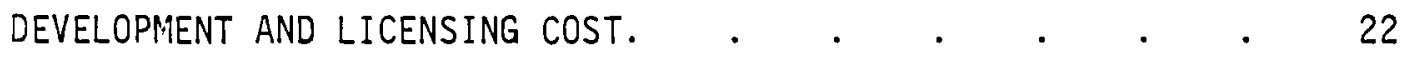

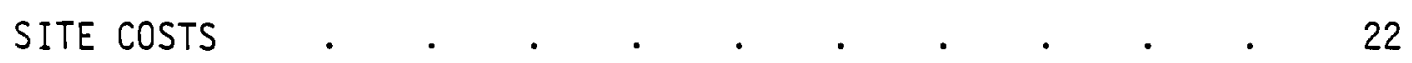

DEMAND LEVELS .

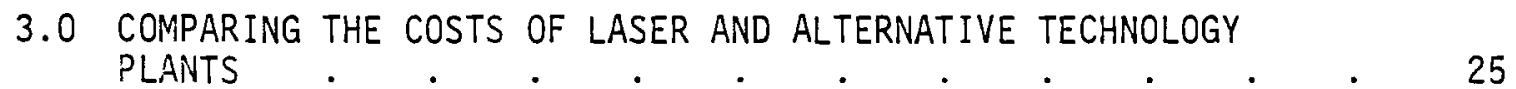

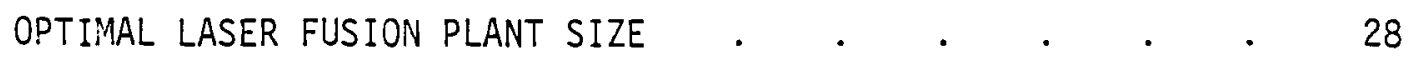

DEBT FROM LASER FUSION INVESTMENTS . $. \quad . \quad . \quad . \quad . \quad$. 28

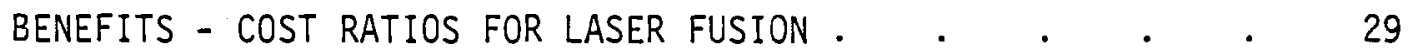

SENSITIVITY OF RESULTS TO SOME KEY FACTORS . . . . . • 31 


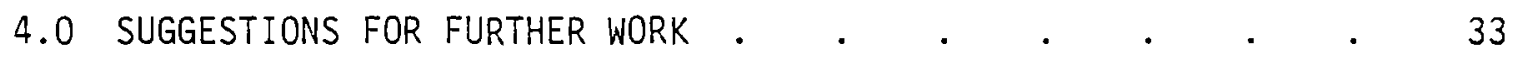

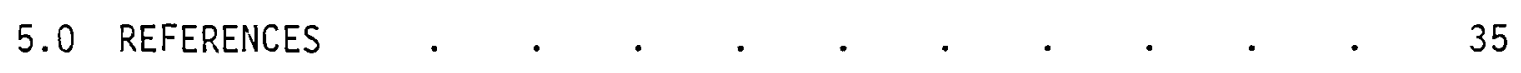

APPENDIX A

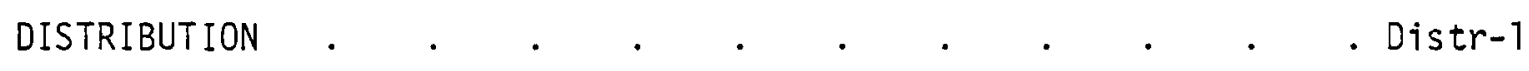




\section{FIGURES}

1 Discounted Lifetime Plant Cost for Each of 4 Alternative Technologies . . . . . . . . . . 3

2a Historical Pattern of LWR Introduction . . . . . 6

2b Pattern of Introduction for Mini-Model with 600 MWe Third Plant . . . . . . . . . . . 6

3 Learning Function . . . . . . . . . 9

4 Economies of Scale: Alternative Functional

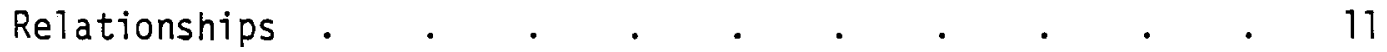

5 Contribution to Total Cost of Component Scaling Effects . . . . . . . . . . 14

6 Determining the Size Distribution of Utility Systems . . 16

7a Forced Outage Rate as a Function of Plant Size . . . 17

$7 b$ Required Reserves as a Function Percentage of a System Due to One Plant . . . . . . . . . 18

8 Electricity Demand Levels Corresponding to Assumed Growth Rates . . . . . . . . . . 24

9 Discounted Lifetime Fusion Plant Costs as a Function of the Number of Years After Commercialization . . . . 26

10 Discounted Net Benefits from Laser Fusion as a

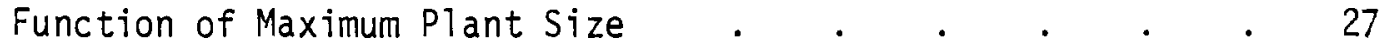

11 Cumulative Benefits as a Function of the Number of Years After Commercialization. . . . . . . 29

12 Benefits of Fusion Power as a Function of First Plant Costs 
. 


\subsection{INTROOUCTION AND OVERVIEW}

This analysis improves upon conventional market penetration studies by focusing upon the optimal laser fusion plant size and its relation to the cost of the first commercial plant. Previous market penetration studies for advanced technologies have focused on either the potential benefits from a design of fixed performance ${ }^{(1-3)}$ or the performance characteristics required for a predetermined benefit leve1. $(4,5)$ This analysis relies on the results of these previous studies in order to define the competitive environment expected to face laser fusion after the year 2000 , but it goes beyond the previous studies by allowing the joint determination of performance characteristics and benefit levels in a "mini-model" constructed just for this purpose. The mini-model draws on the results of many linear programming decision calculations, but is itself nonlinear in nature. Its nonlinearity makes it possible to include such things as learning functions, scale economies, transmission costs and reserve margins which typically are nonlinear in nature. Although the mini-model may capture less detail than the larger models, these larger models cost 50 times as much to operate.

\section{MINI-MODEL OVERVIEW: A COMPARISON OF COSTS}

The basic approach involves comparing the costs of laser fusion plants with the cost of alternative technology plants under a set of basic assumptions. To the extent that the laser fusion costs are less than the alternative technology costs, in the sense defined below, society will benefit from laser fusion. The analysis also allows us to pinpoint some of those assumptions upon which the finding of a benefit may depend.

An earlier report entitled Performance Targets for Fission-Fusion Hybrid Reactors ${ }^{(4)}$ contained a number of base cases without hybrids. Our analysis draws upon this report for four of these base cases to establish the range of costs associated with alternative systems. The next task is then to develop cost estimates for laser fusion plants, which is the objective of Section II of this report. These costs are compared with alternative technology plant costs in Section III of this report. Section IV provides suggestions for further work. 
The comparison of laser fusion and alternative technology plants is based on the discounted value of lifetime costs. Discounted values are simply a means of translating future dollars in different years into dollars in a reference year where they may be properly compared. For example, a dollar now may be invested at, say, $10 \%$ and grow to $\$ 1.10$ a year hence. People do not regard $\$ 1$ a year from now as equivalent to $\$ 1$ now; given the cnoice, they prefer receiving $\$ 1$ a year from now, since if they can get a $10 \%$ return, the $\$ 1$ now would yield $\$ 1.10$ a year from now. People, typically, would be indifferent to $\$ 1.10$ a year from now and $\$ 1$ now, however, if they can get a $10 \%$ return. That is, the discounted value of $\$ 1.10$ a year from now equals $\$ 1$.

Lifetime costs represent the sum total of all costs, including construction funds and operation and maintenance costs. Construction usually takes anywhere from 2 to 10 years and is followed by a long period of operation, which we assume to be 30 years. Plant costs are, therefore, spread out over a long period of time. All costs for a given plant must be properly discounted to a reference year where they may be added together to yield the discounted value of lifetime costs for the reference year. The discounted value of the lifetime costs associated with one plant for that reference year may then be compared to the discounted value of the lifetime costs associated with another plant for that year to determine which is smaller and by how much. All costs are based on constant 1978 dollars; they do not consider inflationary effects.

Figure 1 portrays the discounted value of lifetime costs for each of four cases involving different mixes of alternative generating technologies and the rate of growth of electricity demand. The four cases are: 1) $4.5 \%$ annual demand growth after the year 2000 with only light water reactors and coal-fired plants allowed; 2) $4.5 \%$ annual demand growth after the year 2000 with 1 ight water reactors, coal-fired plants and liquid metal fast breeder reactors allowed; 3) $3.5 \%$ annual demand growth after the year 2000 with light water reactors, coal-fired plants and liquid metal fast breeder reactors allowed; and 4) $3.5 \%$ annual demand growth after the year 2000 with light water reactors, coal-fired plants and liquid metal fast breeder reactors allowed, but assuming the cost of uranium to be half that assumed in cases 1,2, and 3 . In cases 1,2 , and 3 , uranium costs rose to $\$ 100 / 1 \mathrm{~b} U_{3} \mathrm{O}_{8}$ by the year 2000 . 


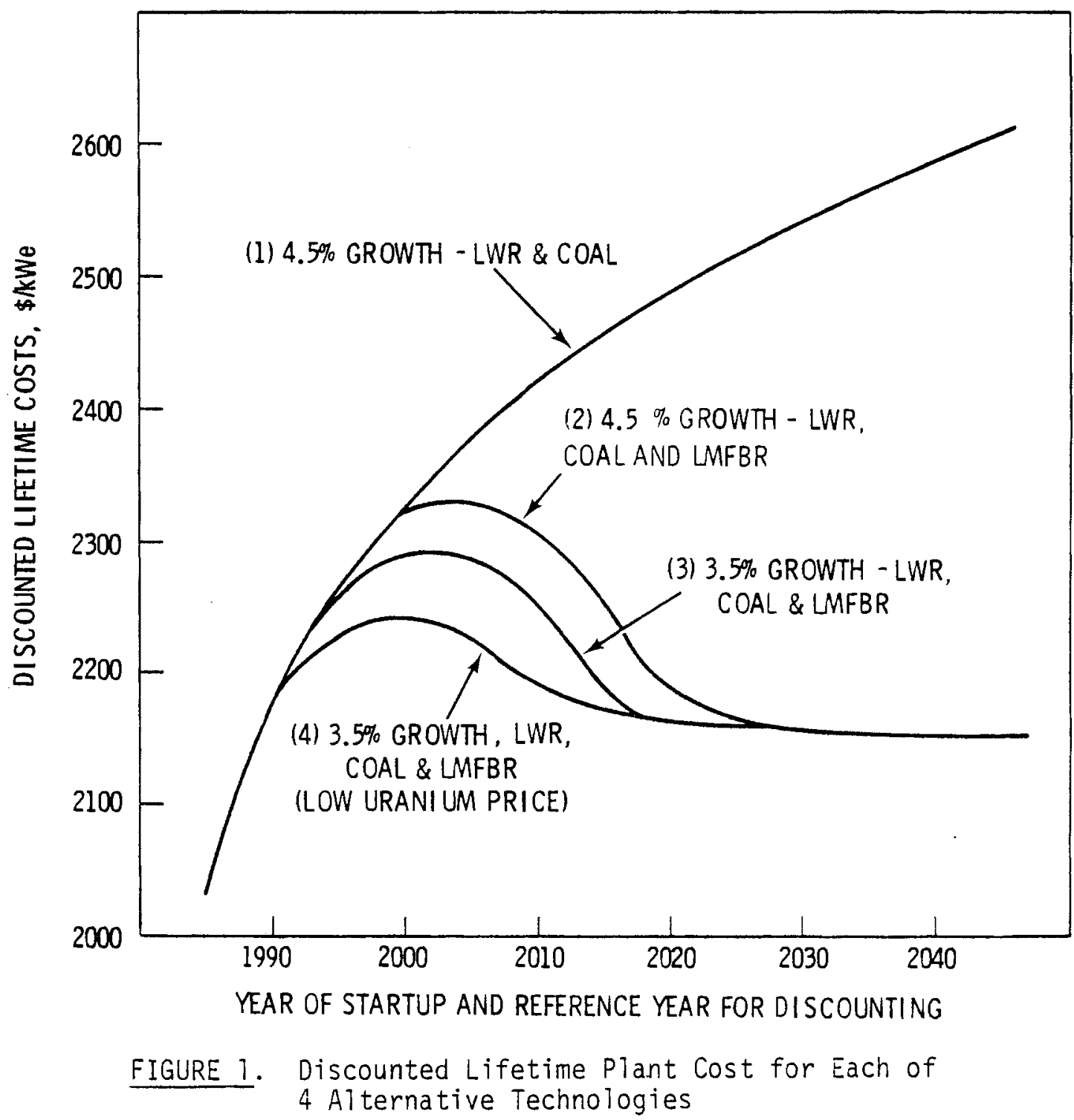

Consider Curve 1 in Figure 1. Each point on this curve represents the discounted value of the lifetime costs of power produced from the plants indicated where the discounting uses the corresponding year on the horizontal axis as the reference year. For example, in the year 2000, Curve 1 indicates a discounted value of slightly over $\$ 2300$ per installed kilowatt. This means that if construction were to begin on such a plant in the year 2000, the lifetime cost for that plant would equal $\$ 2300 / \mathrm{k} /$ when a 11 costs are discounted to the 
reference year 2000. Curve 1 indicates the 1 ifetime costs of such a plant started in the year 2020 would be $\$ 2500 /$ installed $\mathrm{kW}$ when all costs are discounted to the reference year 2020. How consider Curve 4. It indicates that power produced from the case 4 mix of plants will have a lifetime cost of slightly less than $\$ 2200 /$ installed $\mathrm{kW}$ when all costs are discounted to the reference year 2020. The discounted lifetime costs from Curves 1 and 4 for the year 2020 are directly comparable and indicate the mix of plants corresponding to Curve 1 would result in lifetime costs that were $\$ 300$ greater per installed kilowatt when al1 costs are discounted to that year. Curves 2, 3, and 4, therefore, indicate progressively lower (when compared to Curve 1) lifetime costs in each year when all costs are discounted to that year.

The discounted lifetime costs of laser fusion plants are to be compared in each year to the alternative technology costs indicated in Figure 1 . In order to provide a comprehensive assessment of benefits from fusion plants, the yearly differences in discounted lifetime costs are then all discounted to the same reference year, 1978. This enables us to add together the various yearly differences and presents a comprehensive benefit/cost comparison of laser fusion with the alternatives for the year 1978.

It should be noted that we have chosen $10 \%$ as the discount rate for our base case calculations. The choice of a discount rate has always been a subject of much discussion, and the issue has never been resolved. However, the $10 \%$ value for discount rate is currently required by the Office of Management and Budget (OMB). This rate is to be used as the social discount rate in cost benefit studies of this nature. In the sensitivity analysis section of this report, the influence of lower discount rates is examined. 


\subsection{FACTORS AFFECTING THE COSTS OF LASER FUSION PLANTS TO SOCIETY}

Factors that affect the cost of laser fusion power plants include market penetration rate, length of construction period, learning, scale economies, size of the utility's system, reserve requirements, transmission costs, development and licensing costs, site costs, and demand levels. These factors are discussed in the following sections.

\section{MARKET PENETRATION OF LASER FUSION TECHNOLOGY}

The cost of laser fusion plants to society depends upon how many plants are built which, in turn, depends on how rapidly laser fusion plants penetrate the commercial market. Historically, new technologies have all been introduced to the commercial market according to a similar pattern. First, one to three commercial demonstration plants are built. Upon completion, their operating characteristics are examined. The information obtained from this examination is used to plan future growth; it is at this time that orders are placed for future plants. A lag corresponding to the length of the construction period then occurs and is followed by the completion of the plants ordered. The rate of construction of new plants is constrained primarily by the availability of manufacturing capacity. The historical experience with light water reactors, presented in Figure 2a, illustrates this pattern of technology introduction. In this case, one demonstration plant was completed in year 1 and one in year 2 and orders were placed. The third plant was completed in the fifth year. In each of the sixth and seventh years two more new plants were completed, in each of the eighth and ninth years four more new plants were completed, in the tenth year six more new plants were completed and in the eleventh year eight more new plants were completed. By the end of the eleventh year, then, 27 new plants had been completed, based on the orders received after the demonstration plants had been built.

Figure $2 \mathrm{~b}$ illustrates the pattern of introduction of plants embodied in our mini-model. Assume, for simplicity, that demonstration plants were completed in year 1. Orders are placed and the third plant (600 itwe) is completed in year 5 (the length of construction for a 600 WWe plant is estimated in our 


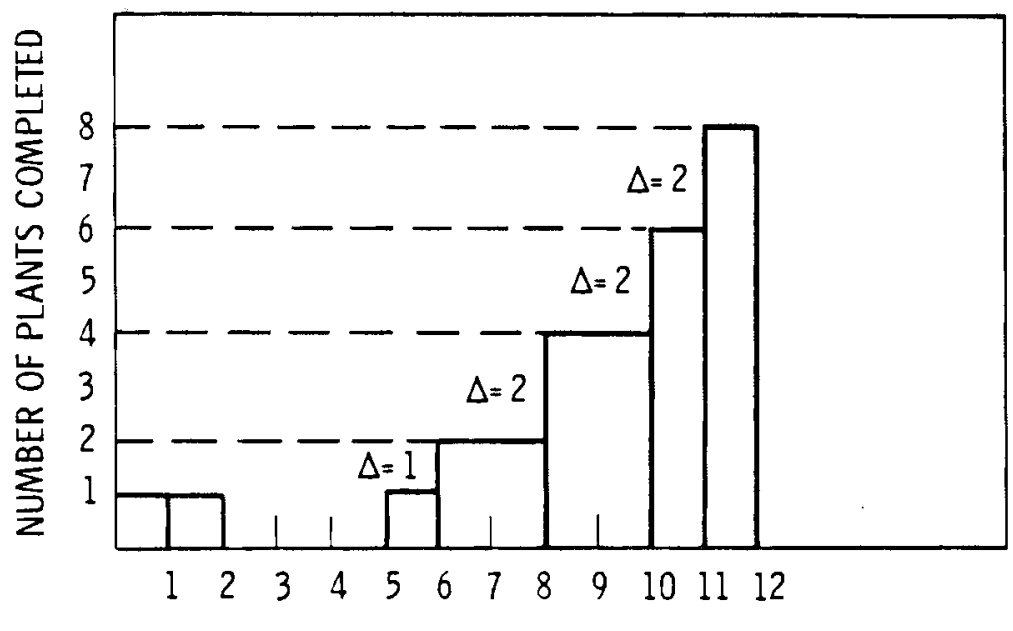

YEAR IN WHICH NEW TECHNOLOGY PLANT IS COMPLETED

FIGURE 2a. Historical Pattern of LUR Introduction

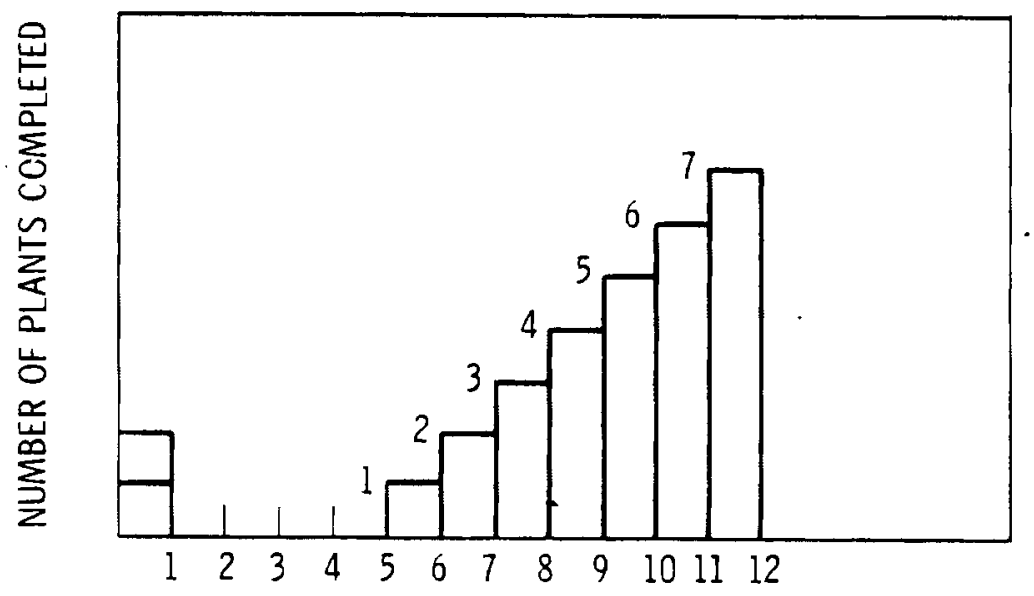

YEAR IN WHICH NEW TECHNOLOGY PLANT IS COMPLETED

FIGURE 2b. Pattern of Introduction for Mini-Model with 600 Mive Third Plant

mini-model to be less than 5 years, according to a formula presented below) and from that time on, new plants are completed according to the following rule: the maximum number of plants completed in any year is one greater than the number of plants completed in the previous year. Using this rule, we find 
that at the end of the eleventh year, a total of 27 new plants has been completed. This.is precisely the same total number of new light water reactor plants actually built by the end of the eleventh year. Although the "step" increase from one year to the next was not actually constant for light water reactors, the end result is the same as that reached upon applying our rule. We, therefore, regard our rule as providing a reasonably accurate representation of the actual rate of introduction. The lag between the time the first demonstration plants are completed and the first of the newly ordered plants is completed will vary depending upon the size of plant, as indicated in the next section.

The maximum share which the new technology plants may have of total new base load plant construction will be influenced by: 1) the utility's desire to diversify; 2) competition with the new technology plants from other sources, and 3) regional price differences. Results from large, linear programming models show that these three factors lead to saturation when the new technology has $35 \%$ of total new base load plant construction. Thus, the maximum height of the bars in Figure $2 b$ will be a number which is $35 \%$ of total new base load plant construction. However, another consideration that will affect the number of new plants a utility decides to build is the size of that new plant relative to the size of the utility's system. This constraint is dealt with in a separate section below.

\section{LENGTH OF CONSTRUCTION PERIOD}

Our mini-model assumes that the length of the construction period is a function of the size of the plant. Therefore, as the size of the plant increases, interest during construction increases as does the lag before building the third plant. The functional form of the relationship is:

$$
T c=a+(S)^{b}
$$

where

$$
\begin{aligned}
T c & =\text { length of construction period (in years) } \\
S & =\text { size of plant in MWe. }
\end{aligned}
$$


The parameters $a$ and $b$ have been estimated from data contained in the iluclear Energy Center studies ${ }^{(6)}$ to be as follows:

$$
\begin{aligned}
& a=-0.78 \\
& b=0.27
\end{aligned}
$$

For example, when $S=1200$ MNe, Tc $=6$ years, but when $S=100$ MWe, then $T c=2.5$ years. This representation assumes that the regulatory situation in 1978 will prevail during the study period.

\section{LEARNING}

Repeated performance of a given activity, in this case, the construction and operation of a new technology plant, increases the efficiency with which that activity is performed. (7) That means the efficiency of plant construction and of plant operation will increase as more plants are built. The findings of Ostwald and Reisdorf ${ }^{(8)}$ and Comotors ${ }^{(9)}$ offer support for this notion. Learning is usually presented as a function of the number of times an activity is repeated; typically, either an exponential or a reciprocal relation is specified. A $90 \%$ learning curve is defined as one in which a doubling of the number of times an activity is repeated results in a $10 \%$ reduction in costs; an $80 \%$ learning curve is one in which a doubling of the number of times an activity is repeated results in a $20 \%$ reduction in costs. Our mini-model assumes that plant cost decreases as the number of plants built increases, according to the following formula:

$$
\frac{C_{t}}{C_{0}}=\frac{1}{N^{a}}
$$

where

$$
\begin{aligned}
C_{t} & =\text { total plant cost in year } t \\
C_{0} & =\text { total cost of the first plant } \\
N & =\text { number of plants built } \\
a & =\text { learning coefficient }
\end{aligned}
$$


Ostwald and Reisdorf estimated the learning curves for nuclear and coalfired plants to be $80 \%$ and $92 \%$ learning curves, respectively, during the first 15 years after introduction. The learning curve for the liquid metal fast breeder reactor plants was estimated to be near $90 \%$. (3) A learning curve of $92 \%$ implies a learning coefficient of .10 in the above specification, which is the value we assume for a. Figure 3 portrays the effect of learning, given $a=.10$. On the vertical axis is the ratio, $c_{i} / C_{0}$, of total plant cost in year $t$ to cost of the first plant. After five plants are built, the total plant cost is $85 \%$ of the first plant cost; after 10 plants, it is less than $80 \%$. After 20 plants have been built, total plant cost approaches $74 \%$ of that of the first plant. This learning curve represents the learning that has occurred over the range of our experience. Obviously, as it becomes very large, the right-hand side above becomes very smal1, approaching zero in the limit.

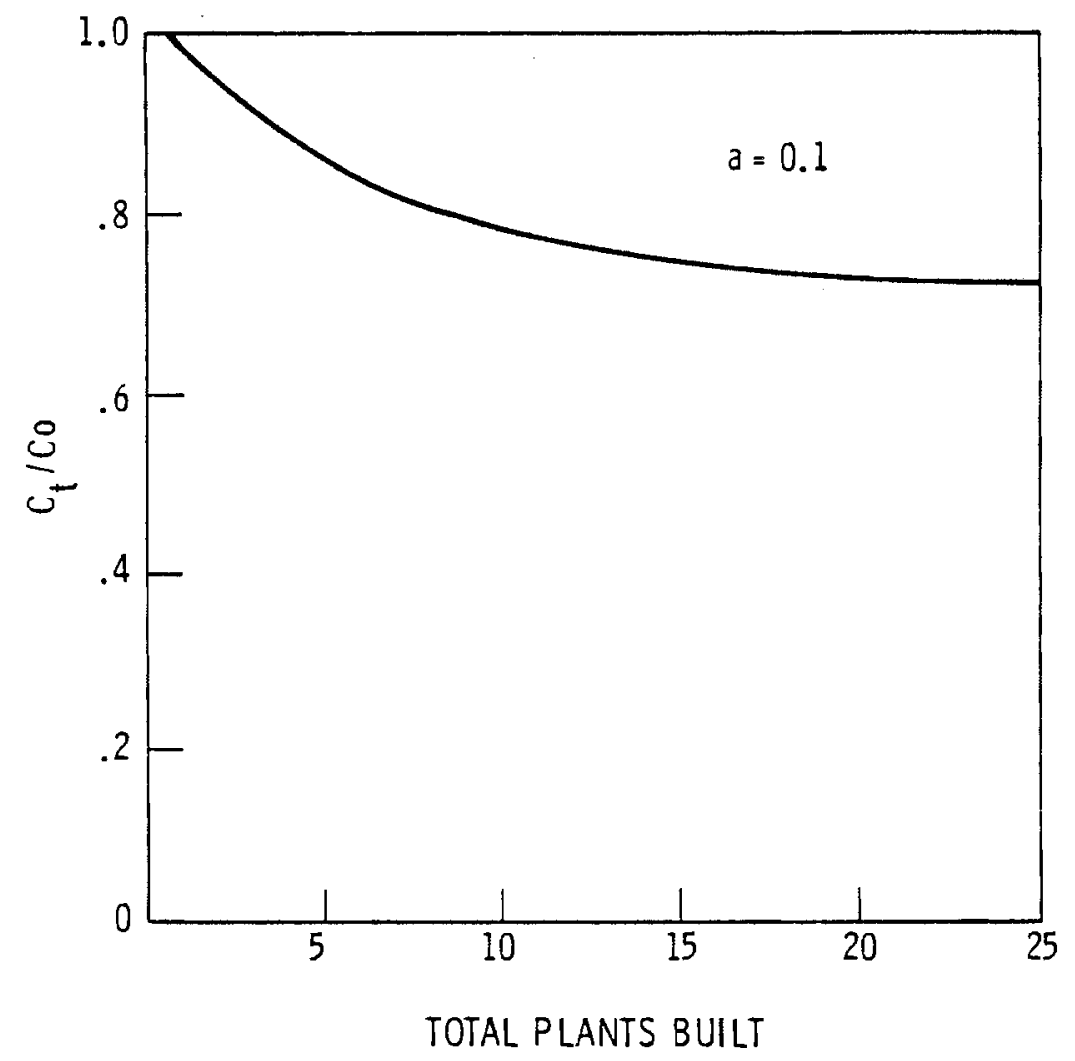

FIGURE 3. Learning Function 
The sizes of in required to produce this result, however, are many times larger than we have experienced. The curve is intended to capture learning effects over the relevant range of experience, so its asymptotic behavior is not relevant.

\section{SCALE ECONOMIES}

As the size of a firm's plant increases, the average cost of each item produced from the plant decreases, up to a point. These reductions in average production costs are generally referred to as "economies of scale". Scale economies do not continue indefinitely as plant size increases; generally, the increasing difficulties of managing larger plants coupled with the scarcity of managerial skills eventually combine to cause average production costs to increase. For our purposes, however, the data indicate that average costs are lower the larger the plant that is built. We assume that scale economies will continue for plants the size of laser fusion plants.

Scale economies are usually represented in the following manner: the cost of production in plant $A$ relative to that in plant $B$ is assumed to be a function of the size of plant $A$ relative to the size of plant $B$. Ir particular,

$$
\frac{\text { Cost of Plant } A}{\text { Cost of Plant } B}=\left[\frac{\text { Size }(\text { Capacity) of Plant } A}{\text { Size (Capacity) of Plant } B}\right]^{P}
$$

where

$$
P=\text { exponential parameter } 0 \leq P \leq 1
$$

The cost per unit of capacity is

$$
\tilde{C}_{A}=\frac{C_{A}}{S_{A}}
$$

where

$$
\begin{aligned}
& C_{A}=\text { Cost of Plant } A \\
& S_{A}=\text { Size of Plant } A .
\end{aligned}
$$

Then

$$
\frac{\bar{C}_{A}}{\bar{C}_{B}}=\frac{C_{A}}{C_{B}}\left(\frac{S_{B}}{S_{A}}\right)
$$


The value of the exponential parameter, $P$, determines how rapidly costs per unit of capacity decrease as plant size increases. Cost per unit of capacity can be scaled by combining the scaling equation with the above expression:

$$
\frac{C_{A}}{C_{B}}=\frac{S_{B}}{S_{A}}\left(\frac{S_{A}}{S_{B}}\right)^{P}
$$

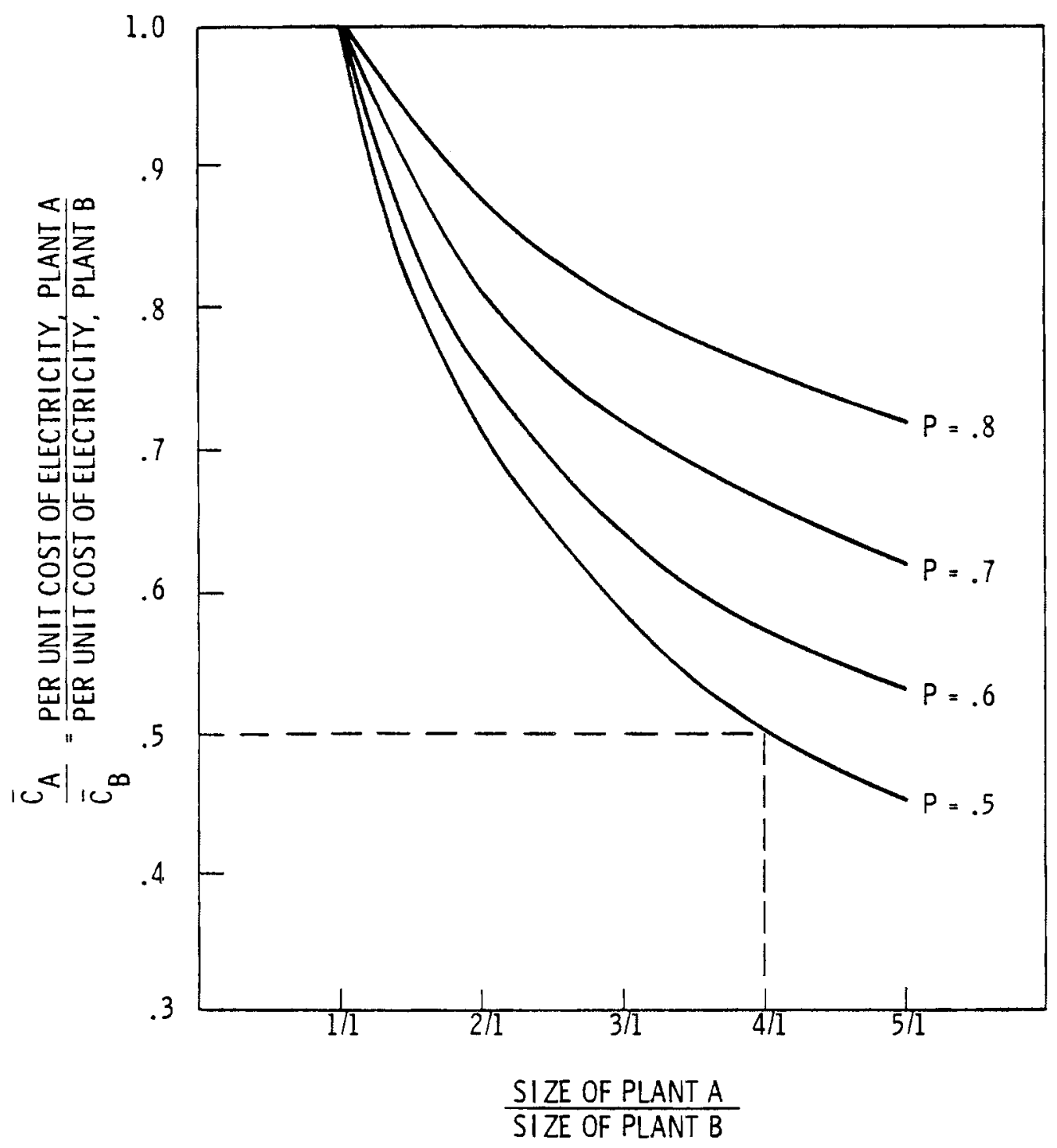

FIGURE 4. Economies of Scale: Alternative Functional Relationships 
Figure 4 represents the effect of various exponential terms on the per unit cost of electricity for several ratios of plant sizes. Suppose $P=.5$, then

$$
\frac{\bar{C}_{A}}{\bar{C}_{B}}=\frac{S_{B}}{S_{A}}\left(\frac{S_{A}}{S_{B}}\right)^{.5}
$$

Further assume that $S_{A}=4 S_{B}$, the size of plant $A$ is four times that of plant $B$. The equation then reduces to

$$
\frac{\bar{C}_{A}}{\bar{C}_{B}}=\frac{S_{B}}{4 S_{B}}\left(\frac{4 S_{B}}{S_{B}}\right)^{.5}=.5
$$

The per unit cost of electricity in plant $A$ is half the per unit cost in plant $B$, as shown in Figure 4.

The historical data indicate that plant size affects the various components of cost differently. We have identified six components of a iaser fusion plant's cost together with their share of a 1 GWe plant's lifetime cost as follows:

Cost Component

Fixed Costs:

Variable Costs:
Nuclear Island

Structure and Facilities

Turbine

Electrical and Other

Fuel

Operation \& Maintenance
Share of Total Cost

$(\%)$

33

17

13

7

24

6

It can be shown that each cost component is affected by scale economies differently. In other words, 


$$
\frac{C_{i A}}{C_{i B}}=\frac{\text { Cost of Component } i(\text { Unit } A)}{\text { Cost of Component } i(\text { Unit } B)}=\left[\frac{\text { Size } A}{\text { Size } B}\right]^{P_{i}}
$$

where $P_{i}=$ exponential parameter for component $i$. The component costs can be combined to determine each component's contribution to the per unit cost of generation for a given plant size. The relation for determining the scaled component costs contribution is given as a technical note in Appendix $A$.

Estimates of these cost components for fusion hybrid plants of 500 MWe and 1200 MWe were used to derive the scaling exponent, ${ }^{(10)} P_{i}$, displayed below:

Cost Component $\left(C_{i}\right) \quad$ Estimated Value of Exponent $\left(P_{i}\right)$

$\begin{array}{ll}\text { Nuclear Island } & .63 \\ \text { Structure } & .7 \\ \text { Turbines } & .85 \\ \text { Electrical } & .75 \\ \text { Fuel } & .50 \\ \text { Operation \& Maintenance } & .7\end{array}$

The greatest scale economies are associated with fuel (for which the scaling exponent $P_{i}$ has the lowest value) and the least scale economies are associated with turbines (having the highest $P_{j}$ value).

The cumulative effort of applying the scaling equation for each of the components is shown in Figure 5. The share of total cost for each component is accumulated in the figure. As shown, when the ratio of plant sizes is 1 to 1 , the nuclear island's contribution is $33 \%$, the structure is $17 \%$, etc. For differing ratios of plant sizes, the effect of scaling causes the proportional contributions of each component to the total cost to change. The figure shows the total scaling effect resulting from each component. For example, for a ratio of plant sizes of 4 to 1 , the total scaling is approximately 0.58 as marked by the asterisk on the figure. The proportional contribution of each component can then be determined from the differences between the cumulative component shares. 


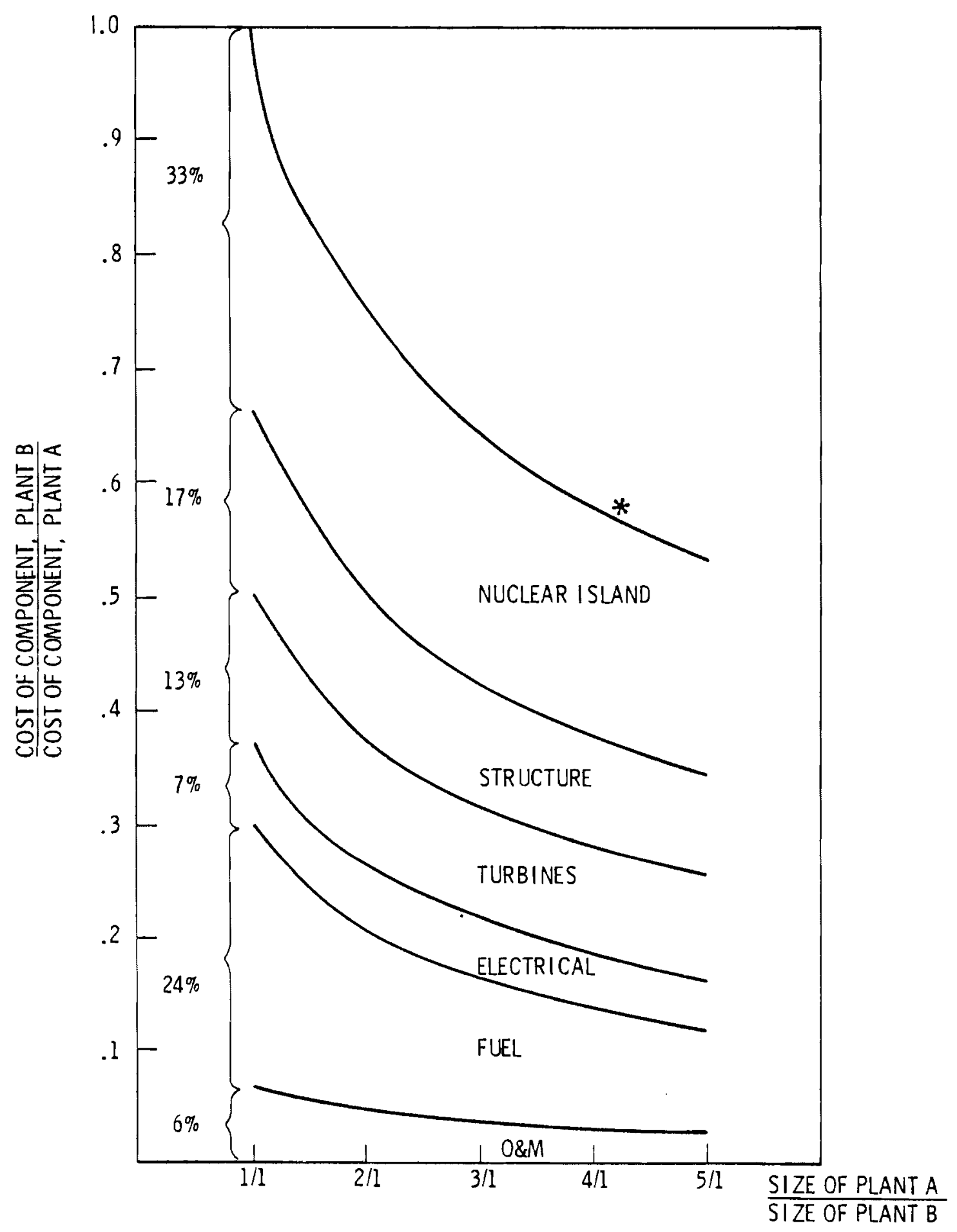

FIGURE 5. Contribution to Total cost of Component Scaling Effects 
THE SIZE OF THE UTILITY'S SYSTEM

It is a generally accepted system reliability requirement that no more than $10 \%$ of a system's capacity should be provided by a single plant. Thus, the market penetration of laser fusion plants will depend on the size of these plants relative to the size of the systems to which there may be additions. This represents an additional constraint on the market penetration of laser fusion plants. In order to incorporate this constraint into the analysis we need to have some method for determining system size. The following paragraph describes that method.

Consider only the largest $70 \%$ of a 11 existing utility systems. (The smallest $30 \%$ of all plants are not expected to represent a significant part of the market for laser fusion plants.) For each system note its size and the percentage its generating capacity is of the generating capacity of all these systems combined. In general, the relationship between these two factors is similar to that displayed in Figure 6 , which assumes demand grows at $3.5 \%$ annually. The largest individual system expected in the year 1985 is over 10,000 megawatts. We define the nominal system size to be equal to half the size of the largest system. Approximately $35 \%$ of all generating capacity is then expected to be from systems larger than the nominal size, and $65 \%$ from systems smaller than the nominal size. The point on the horizontal axis corresponding to the nominal size is referred to as the centroid of the points on the horizontal axis.

We simply assume that the shape of this function in future years will be such that the centroid will remain unchanged. In other words, we assume that $35 \%$ of al1 the generating capacity will come from systems larger than the nominal size and 65\% will come from systems smaller than the nominal size. We further assume that utilities will interact in the financing and use of new capacity and that the size of these utility consortia will be equal to 3 times the nominal utility size. Typical 1978 consortium sizes are about twice the nominal size, so this assumption will allow relatively larger consortia to be formed than have been in the past. The reason for making this assumption is that economies of scale are expected to be significant in connection with laser fusion plants; this should provide an incentive for the relative size of consortia to increase. 


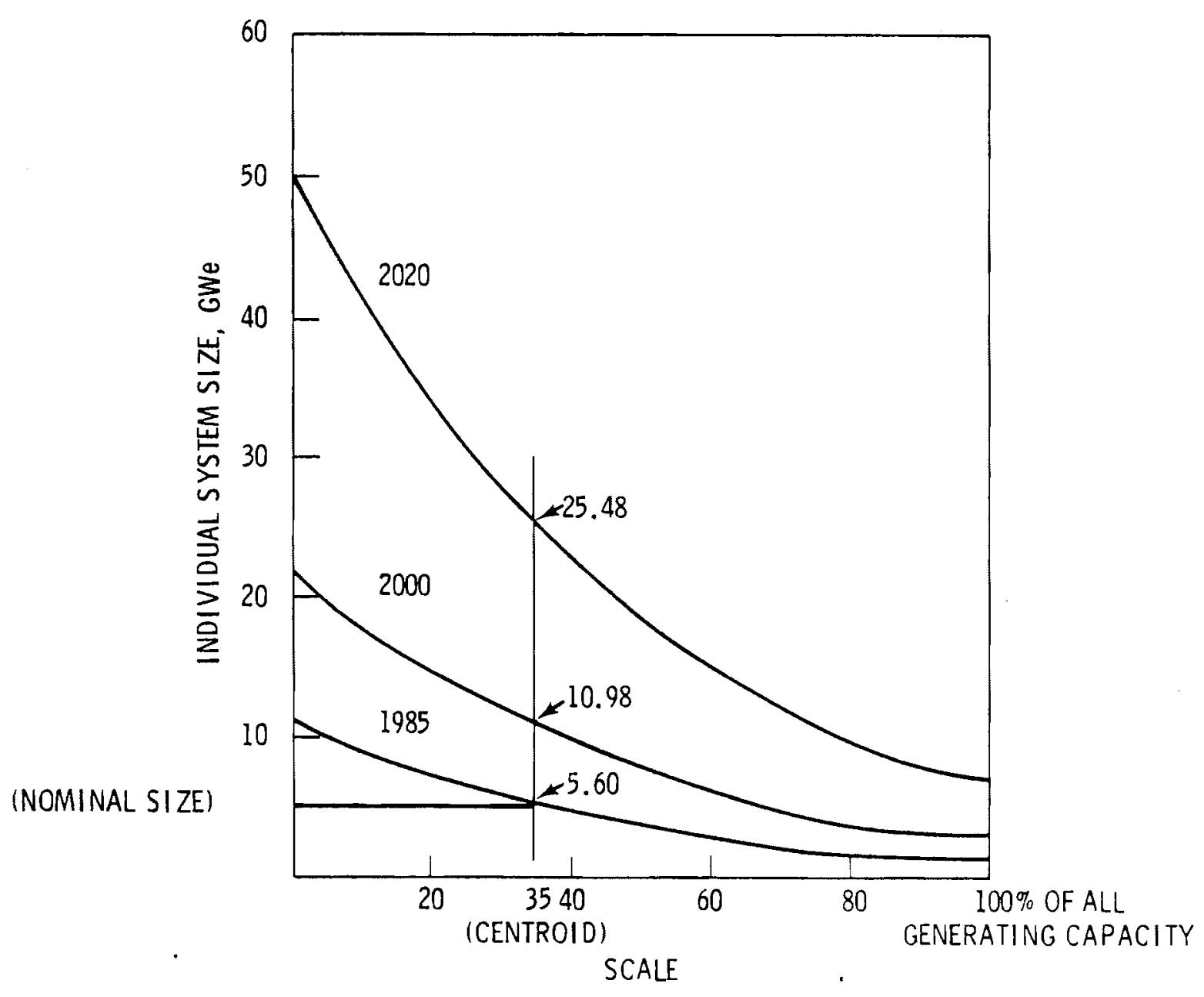

FIGURE 6. Determining the Size Distribution of Utility Systems (assuming $3.5 \%$ annual growth in demand)

These above considerations allow us to determine the future size distribution of utility systems and consortia, which will act as an additional constraint upon the market penetration of laser fusion plants.

\section{RESERVE REQUIREMENTS}

In addition to the requirement that no plant represent more than $10 \%$ of system capacity, system reliability requires that a certain amount of reserve capacity be installed to carry the load when there are forced outages, when 
scheduled maintenance occurs or to guard against load forecasts which turn out to be lower than actual loads. The costs associated with reserves must be considered.

For the most difficult laser fusion introduction scenario (i.e., largest plant size--6 GWe--coupled with the lowest system growth rate--3.5\% and year 2000 introduction) the number of consortia (of size equal to 3 times the nominal utility size) participating in the market must be about 20 . But when the consortium size is divided into the capacity required in any year, the number of possible consortia are found to be about 40 . Thus, in the worst case situation there would still be twice as many potential consortia as are needed so that no more than $10 \%$ of the generating capacity will be maintained in a single generating unit. During the early 1970s, 52 consortia were formed to capture the economies of scale offered by the light water reactor technology. Consortia owned 30\% of all plants sold through 1975.

The reserve requirements for a utility are also affected by the forced outage rates of each of the individual generating units. Historical data on plant operations indicate that as plant sizes become larger, the forced outage rate tends to increase.

Figure $7 a$ presents the considerations entering into the determination of reserve requirements based on a report by G.E. (11) Only forced outage rates are considered here because they are directly related to plant size. The effects

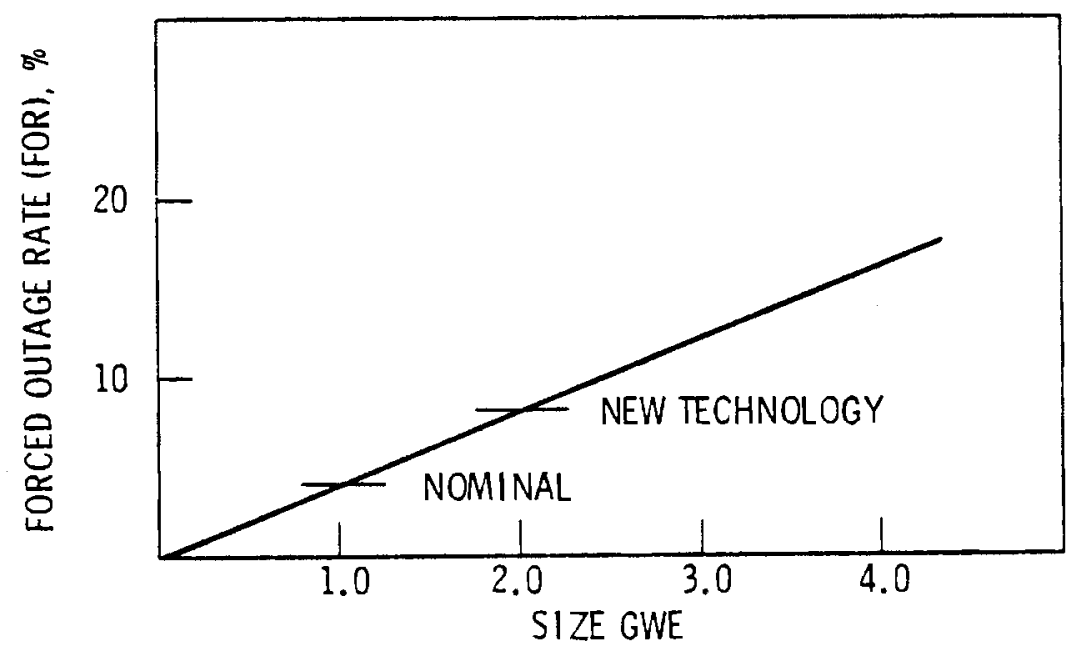

FIGURE 7a. Forced Outage Rate as a Function of Plant Size 
of scheduled maintenance and load forecasting error are assumed to be the same for laser fusion plants and the next best alternative. Figure 7a indicates a direct linear relationship between forced outage rates and plant size. For a plant the size of 1 GWe, corresponding to the current technology, the forced outage rate equals $4 \%$, but for a plant size of 2 GWe, corresponding to future technology, the forced outage rate is expected to be $8 \%$. The equation yielding these results is:

$$
\text { F.O.R. = } k \text { (size in GWe) }
$$

where

$$
\begin{aligned}
F .0 . R . & =\text { forced outage rate, as a percent } \\
k & =4
\end{aligned}
$$

Figure $7 b$ indicates the relation between required reserves and the percentage of the system represented by that plant. For plants comprising the same percentage of system capacity, we expect different reserve requirements depending on the size of the plant, hence, depending on the forced outage rate.

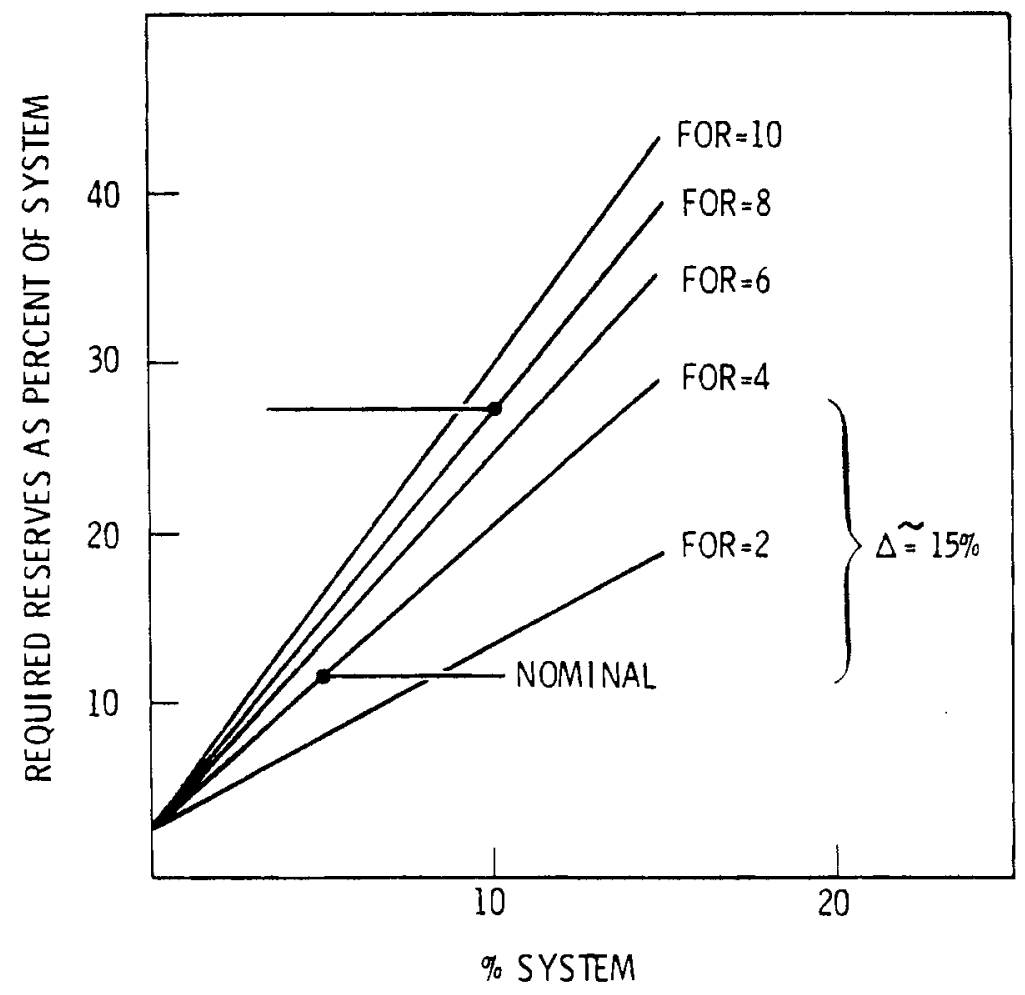

FIGURE 7b. Required Reserves as a Function Percentage of a System Due to One Plant 
For example, consider a 1 GWe plant representing $4 \%$ of a system's capacity. Figure $7 a$ tells us this plant will have a $4 \%$ forced outage rate and Figure $7 \mathrm{~b}$ tells us that a plant representing $4 \%$ of a system and having a $4 \%$ forced outage rate will require approximately $12 \%$ of its capacity as a reserve. But a 2 GWe plant representing $10 \%$ of the system will have a forced outage rate of $8 \%$ according to Figure $7 \mathrm{a}$ and will require about $27 \%$ of its capacity as reserve. The difference of $15 \%(27 \%-12 \%)$ represents the increase in reserve requirements associated with the larger plant. We assume this additional capacity will be provided to the system by adding more capacity of the existing technology; the cost of this additional capacity represents the added cost of the required reserves for the larger plant.

\section{TRANSMISSION COSTS}

Laser fusion plants ranging from 2 Gwe to 10 GWe could increase transmission costs (in comparison to conventional nuclear plants of about 1.2 GWe in size) to the extent they are located farther away from the load center. Al though the "Nuclear Energy Site Survey - 1975"(6) did not show a strong incentive for conventional nuclear plants to be located in nuclear energy centers (NEC), the report analyzed transmission costs for sites ranging from 4 Gie to 48 GWe in size. The Site Survey found the following factors to have the greatest influence on transmission costs:

- the load density, since it affects transmission distance and backup for transmission reliability

- the location of sources of cooling water

- the trend toward multiple conventional units at one site.

Factors found to be of lesser importance include:

- the distance from the load center

- the availability of land

- other site considerations such as air quality

- the extent to which 1985 transmission systems could serve as a backup to transmission lines for large generating stations. 
Our analysis assumes that the site for laser fusion plants will consist of two plants (of whatever size) and that the site for the alternative technology will consist of two plants, 2 GWe each in size. The "Nuclear Energy Site Survey" site consisted of four 1.2 GWe light water reactors. Our assumption about the capacity of the typical alternative technology site is, therefore, very similar to the Survey. This enables us to utilize the Site Survey estimates of the average added transmission distances to load centers of varying load densities. Table 1 presents some of these Site Survey estimates.

TABLE 1. Site Survey Estimates of Added Transmission Distances (Added miles relative to a 4.8 GWe site)

\begin{tabular}{|c|c|c|c|}
\hline \multirow[b]{2}{*}{$\begin{array}{c}\text { Site } \\
\text { Capacity } \\
\end{array}$} & \multicolumn{3}{|c|}{ Load Density } \\
\hline & $\begin{array}{l}\text { Low } \\
\text { (Western } \\
\text { States) }\end{array}$ & $\begin{array}{l}\text { Moderate } \\
\text { (East Centra1 } \\
\text { States) }\end{array}$ & $\begin{array}{c}\text { High } \\
\text { (Northeast } \\
\text { States) } \\
\end{array}$ \\
\hline 12 GWe & 130 & 60 & 40 \\
\hline 24 GWe & 190 & 80 & 40 \\
\hline
\end{tabular}

The only difference is that we assume the conventional capacity will be developed from two plants of 2 GWe each instead of four plants of 1.2 GWe each. Since the chances of two plants experiencing a forced outage simultaneously are greater than the chances of four plants experiencing a forced outage simultaneously, our assumption means more reserve capacity will be needed for the conventional site.

The Site Survey estimates of added transmission distances have been used to derive a more precise statement of the relation between the capacity of the plant and the transmission distance associated with that capacity. The equation below was designed for the average load density in the U.S.

$$
T .0 .=\frac{150}{1+\frac{2000}{S}}
$$

where 


$$
\begin{aligned}
\text { T.D. } & =\text { transmission distance } \\
S & =\text { size of plant, MWe }
\end{aligned}
$$

therefore,

$$
\text { A.T.D. }=\frac{150}{1+\frac{2000}{S_{A}}}-\frac{150}{1+\frac{2000}{S_{B}}}
$$

where

$$
\begin{aligned}
\text { A.T.D. } & =\text { added transmission distance } \\
S_{A} & =\text { size of laser fusion plant, MWe } \\
S_{B} & =\text { size of alternative technology plant, MWe }
\end{aligned}
$$

In the event the two plants are the same size, the two terms on the righthand side are equal and the added transmission distance is zero. Suppose, however, that $S_{A}=4000$ MWe and $S_{B}=2000$ MWe. The first term on the righthand side reduces to $\frac{150}{1.5}=100$ miles and the second term to $\frac{150}{2}=75$ miles. The added transmission distance for the larger fusion plant, therefore, equals 25 miles. The 4000 MWe fusion plant will be located 25 miles further from the typical load center than the 2000 MWe conventional plant. In the event that $S_{A}=1000$ and $S_{B}=2000$, the added transmission distance would be negative 25 miles, indicating the 1000 Mwe fusion plant would be located 25 miles closer than the 2000 M.We conventional nuclear plant.

With an estimate of the added transmission distance associated with a given capacity fusion plant, we may proceed to estimate the cost of that added transmission distance. The Site Survey found that 1974 transmission costs for a 12 GWe site would average $6 \%$ of total cost in the West and $3.6 \%$ of total costs in the rest of the country; for a 48 Gle site the estimates were $9 \%$ of total costs in the West and $4 \%$ of total costs in the rest of the country. We shall assume transmission costs amount to $5 \%$ of total costs. Using Figure 1 we see that $\$ 2300$ represents a reasonable estimate of the yearly total cost for each installed kilowatt of alternative technology power. This means transmission costs per mile equal $(.05)(2300)=\$ 115$ per kilowatt. This agrees with the high range of cost found by Richardson. (12) The above formula indicates a 2000 MWe alternative technology plant will be 75 miles from the load 
center. This means a $\frac{115}{75}=\$ 1.52$ per mile per kilowatt transmission cost for the alternative technology plant. The added transmission cost for the laser fusion plant is assumed to equal this $\$ 1.52$ per mile cost per kilowatt multiplied by the difference in mileage. For laser fusion plants located closer to the load center than the alternative technology plants, this will represent a cost saving.

\section{DEVELOPMENT AND LICENSING COST}

Each time the maximum size of a laser fusion plant is increased by 1000 MWe, we assume there will be additional development costs and additional licensing costs. This added cost is assumed to be distributed equally over each kilowatt of installed capacity. The repayment of total development and licensing costs includes interest from the time of initial investment until the plant is sold. The formula below is used to estimate these added costs.

$$
\text { A.D.C. }={\frac{\text { T.D.C. }(D R)^{t-t o}}{N}}^{\text {to }}
$$

where

$$
\begin{aligned}
\text { A.D.C. = } & \text { added development and licensing costs, millions of } \\
& \text { dollars, per } \mathrm{kW} \\
\text { T.D.C. }= & \text { total development and licensing costs } \\
t= & \text { current year } \\
\text { to }= & \text { first year of increased plant size } \\
N= & \text { total number of plants sold by the increased size } \\
D R= & 1+\text { discount rate }
\end{aligned}
$$

Available estimates $(13,14,15)$ based on development and commercialization of light water reactors indicate that average added development and licensing costs to bring a larger plant into production range from $\$ 200$ to $\$ 400$ million.

\section{SITE COSTS}

The ivclear Energy Site Survey found ample supply of sites with capacity to handle 4 GWe to 5 GWe each. Although this study only went through the year 
2000 , the growth rate was much higher than the current projections ( 850 GWe vs. 280 GWe nuclear capacity). As the capacity of each site was increased up to 48 GWe, limits began to develop. High capacity sites could have problems with transmission corridors and weather modifications. No economic incentive was found for sites larger than 24 GWe, but these estimates did not include economyof-scale effects. The availability of large sites was found to be regional in nature (i.e., limits already exist in the mountain states due to 1 imited availability of water). Concern for site shortages after the year 2000 was noted by DeBellis ${ }^{(16)}$ last year. ilo other comparable study dealing with the period past the year 2000 was found to exist; thus, physical site limits will be examined by reducing the base case number of sites to assess the impacts on output values. Limiting the number of sites of larger size forces the system to build smaller plants.

\section{DEMAND LEVELS}

Two alternative demand scenarios are specified: 1) demand increasing exponentially at $4.5 \%$ per year, 2) demand increasing exponentially at $3.5 \%$ per year. Figure 8 presents the annual demand levels corresponding to these two assumptions. The addition of laser fusion plants is constrained to be in integral numbers of plants of the specified size. If the demand increase is for less than a full plant in one year, for example, a plant may be built then but the excess capacity built is noted and enters into the decision to build another plant. 


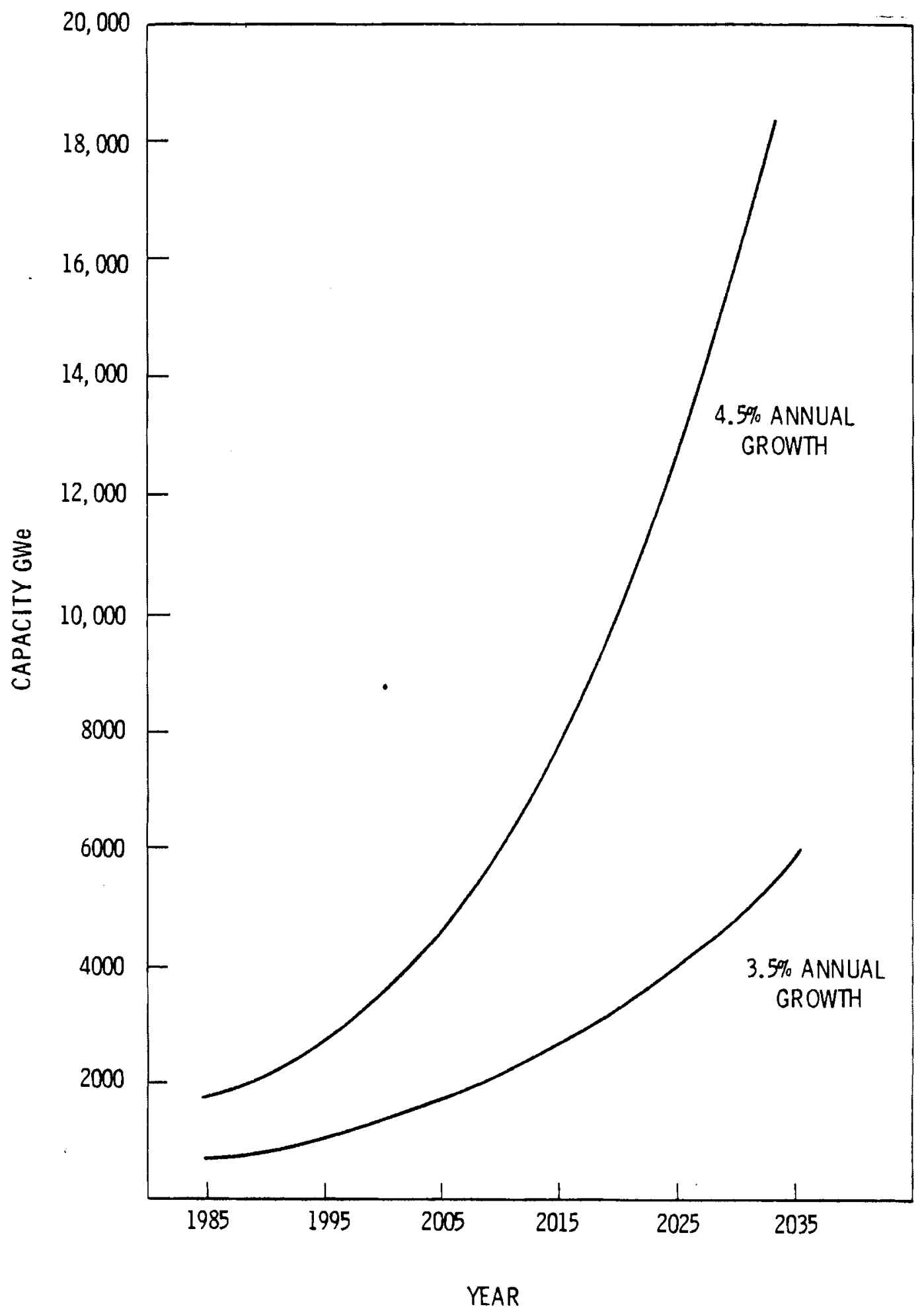

FIGURE 8. Electricity Demand Levels Corresponding to Assumed Growth Rates 


\subsection{COMPARING THE COSTS OF LASER AND ALTERNATIVE TECHNOLOGY PLANTS}

A major objective of this investigation is the determination of the optimal size for laser fusion plants. Our mini-model can be used to make this determination. Net benefits from laser fusion debt from fusion investments, benefit-cost ratios for fusion and sensitivity of some of our results are also examined.

\section{THE NET BENEFITS FROM LASER FUSION}

The determination of optimal plant size must focus on the cost of laser fusion plants of various sizes relative to the cost of al ternative technology plants. For purposes of discussion, let case (3) in Figure 1 represent the alternative technology. Next, suppose that the first laser fusion plant costs $\$ 3200 / \mathrm{kW}$, an arbitrarily chosen amount. Then, for each of several plant sizes, plot the relationship between discounted laser fusion plant costs and the number of years after the commercial entry of laser fusion (assuming laser fusion enters in the year 2000). Figure 9 presents such a plot for laser fusion plant sizes of 1 GWe, 2 GWe, and 6 GWe. The dotted horizontal line in Figure 9 represents the alternative technology cost from the year 2000 on.

The discounted laser fusion plant cost curves presented in Figure 9 each decline due to the effects of learning. For a 1 Gle size laser fusion plant, learning reduces discounted plant cost from $\$ 3200 / \mathrm{kW}$ initially to $\$ 1619 / \mathrm{kW}$ after 35 years for a reduction of $49 \%$, for example. The differences between the four curves for laser fusion plants can be attributed to economies of scale. The discounted costs after 35 years would be $\$ 1177$ for a 3 GWe plant and $\$ 973 / \mathrm{kW}$ for a 6 GWe plant compared to $\$ 1308 / \mathrm{kW}$ for a 2 GWe plant. Thus, a tripling of plant size from 2 GWe to 6 GWe would reduce discounted costs after 35 years from $\$ 1300 / \mathrm{kW}$ to $\$ 950 / \mathrm{kW}$, a reduction of $27 \%$. It is interesting to note that the cost reductions resulting from learning are considerably greater than those resulting from scale economies.

The essential ingredients for the determination of optimal laser fusion plant size may now be indicated. Consider the difference between the alternative technology plant curve and the 2 GWe laser fusion plant curve in Figure 9. 


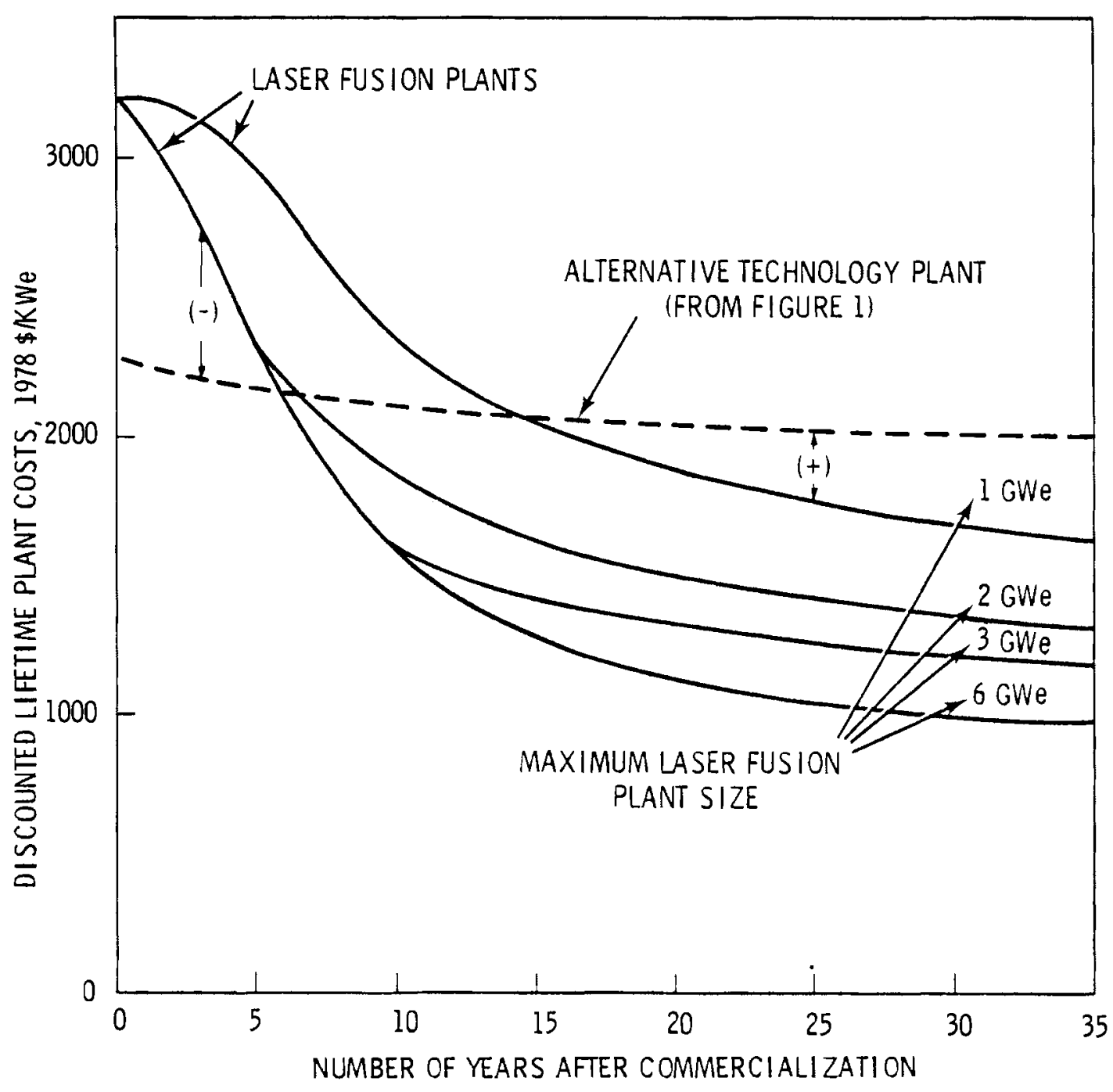

FIGURE 9. Discounted Lifetime Fusion Plant Costs as a Function of the Ilumber of Years After Commercialization

During the first few years after laser fusion commercialization, this difference is negative since the laser fusion plant is more expensive. After the fifth year, however, the difference is positive, since the laser fusion plant is cheaper than the alternative. To determine whether a 2 GWe laser fusion plant would yield net benefits to society over the alternative technology, we must calculate these differences in each year after the entry of laser fusion, multiply each difference by the number of laser fusion plants built in that 
year, discount each of these differences to a common reference year (which we have taken to be 1978) and then add all these numbers together. The result will be termed the discounted net benefits to society from laser fusion plants. A similar set of calculations may be performed for a number of al ternative laser fusion plant sizes. Since the assumption of a $\$ 3200 / \mathrm{kW}$ first plant cost was arbitrary, another set of discounted net benefit calculations could be performed using different assumptions about the cost of the first plant. Figure 10 presents discounted net benefit curves assuming initial plant costs of $\$ 2400 / \mathrm{kW}, \$ 3200 / \mathrm{kW}$ and $\$ 4000 / \mathrm{kN}$. For each of these curves, the discounted net benefit is calculated assuming laser fusion plant sizes of 1 GWe, 2 GWe, 3 GWe, 4 GWe, 5 GWe and 6 GWe.

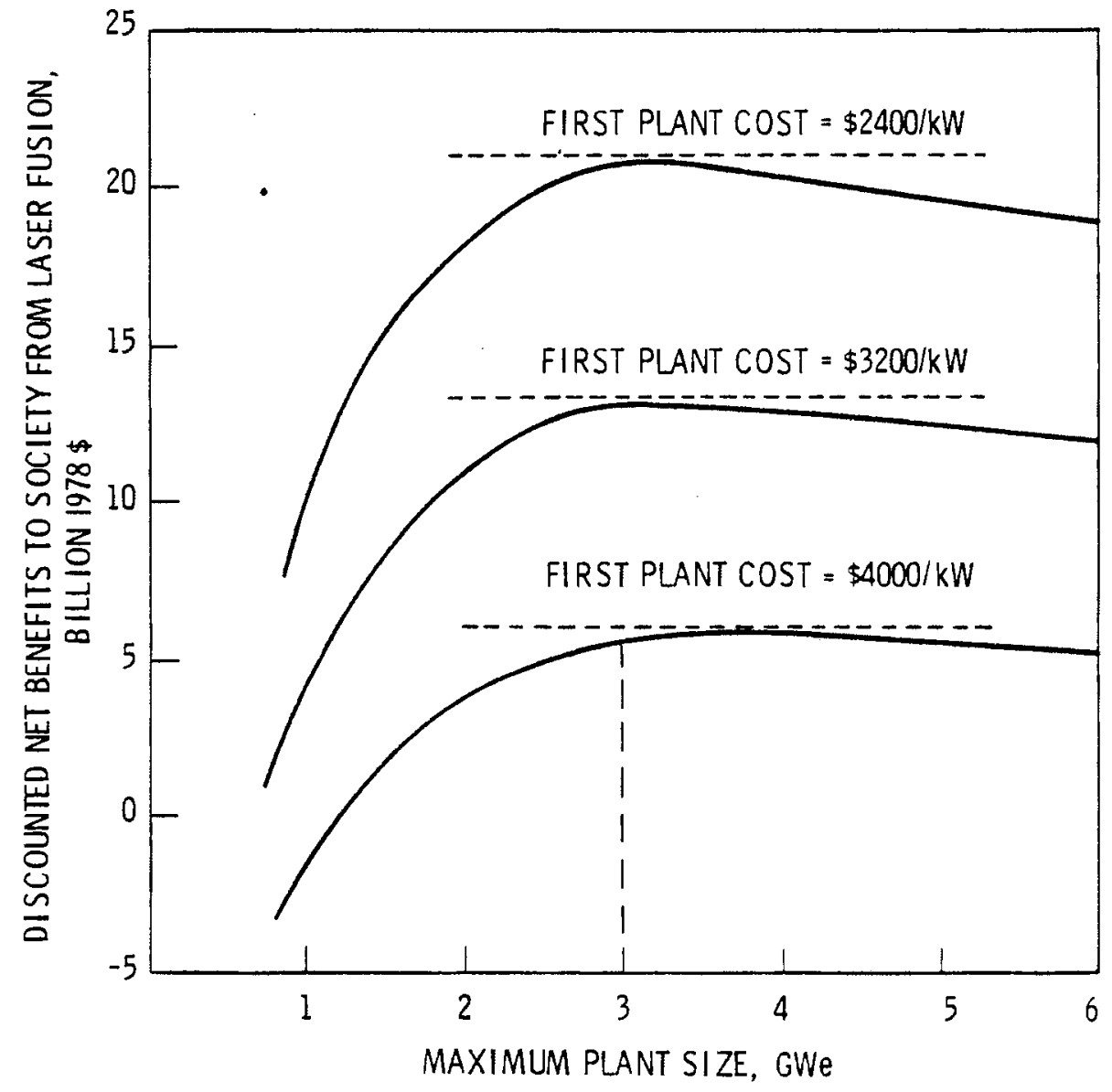

FIGURE 10. Discounted Net Benefits From Laser Fusion as a Function of Maximum Plant Size 


\section{OPTIMAL LASER FUSION PLANT SIZE}

The curves in Figure 10 indicate that discounted net benefits to society from laser fusion increase for each size of plant as the cost of the first plant decreases, as we would expect. If the maximum laser fusion plant size is 1 GWe, discounted net benefits are negative assuming the first plant costs $\$ 4000 / \mathrm{kW}$, but positive assuming the first plant costs $\$ 3200 / \mathrm{kW}$ or $\$ 2400 / \mathrm{kW}$. A11 three curves display a similar pattern, however. The point of maximum benefit to society is achieved for each curve when the plant size equals 3 GWe. In contrast, the benefit level corresponding to a 2 GWe size plant is much less than the maximum, amounting to only $40 \%, 44 \%$ and $62 \%$ of the maximum, for the lowest to the highest curves, respectively. Since our mini-model does not capture all the risks which must be considered in choosing the size of plant, a safe strategy would seem to be that which chooses 3 GWe.

The major objective of this investigation has now been accomplished. However, there are some other interesting results which merit discussion.

\section{DEBT FROM LASER FUSION INVESTMENTS}

The federal government might want to know how long it would be before the cumulative net benefits would be positive and how large would be the total losses to society experienced up to that point. Figure 11 presents the cumulative benefit curves corresponding to the three specified initial plant costs; we are assuming the maximum laser fusion plant size to be 3 GWe. In the case of an initial plant cost of $\$ 3200 / \mathrm{kW}$ the cumulative net benefit becomes positive in the sixth year after commercialization; a cumulative loss to society amounting to $\$ 208$ million is experienced up to this point. In the case of an initial plant cost of $\$ 4000 / \mathrm{kW}$, the cumulative net benefit becomes positive only after the 15th year, during which time a loss to society amounting to $\$ 0.9$ billion will be experienced. This situation probably represents the limits of acceptability of the laser fusion technology by the utility industry as well as the limits of the public's willingness to subsidize the technology. In the case of an initial cost of $\$ 2400 / \mathrm{kW}$, which represents the cost of the alternative technology in the year 2000, no losses to society are experienced. However, it is unlikely that a new technology could be introduced such that its cost was 
equal to that of the alternative. Thus, it would appear reasonable to conclude on the basis of these results that society might need to spend up to $\$ 0.2$ billion to subsidize the construction of the first three laser fusion plants.

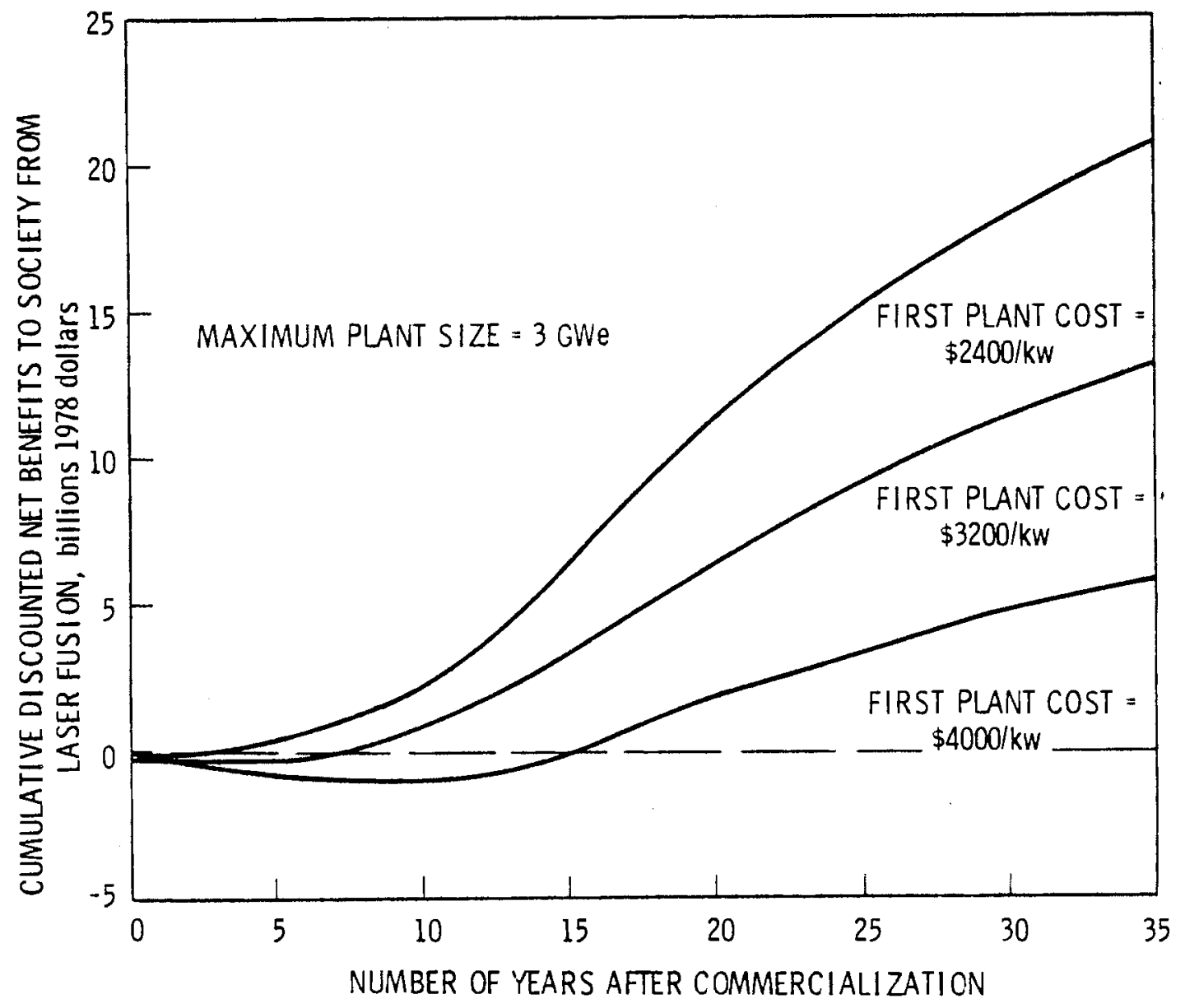

FIGURE 11. Cumulative Benefits as a Function of the Number of Years After Commercialization

\section{BENEFITS - COST RATIOS FOR LASER FUSION}

The laser fusion program is expected to cost about $\$ 10$ to $\$ 15$ bi11ion $(17,18)$ for research and development. Research and development costs discounted at $10 \%$ would be about $\$ 3$ and $\$ 5$ billion respectiveiy. Discounted dollars may be 
directly compared with the net benefits to society, yielding a benefit-cost ratio for the base case from 2.6 (the lowest - $\frac{13 \text { Benefit }}{5 \text { Cost }) ~ t o ~} 4.3$ (the highest $-\frac{13 \text { Benefit }}{3 \text { cost }}$. The typical target benefit-cost ratio is anywhere from 3 to 10; most of the cases considered here would yield ratios in this range or better.

Another approach to these same figures is possible using Figure 12, which plots the net benefit to society as a function of the cost of the initial plant.

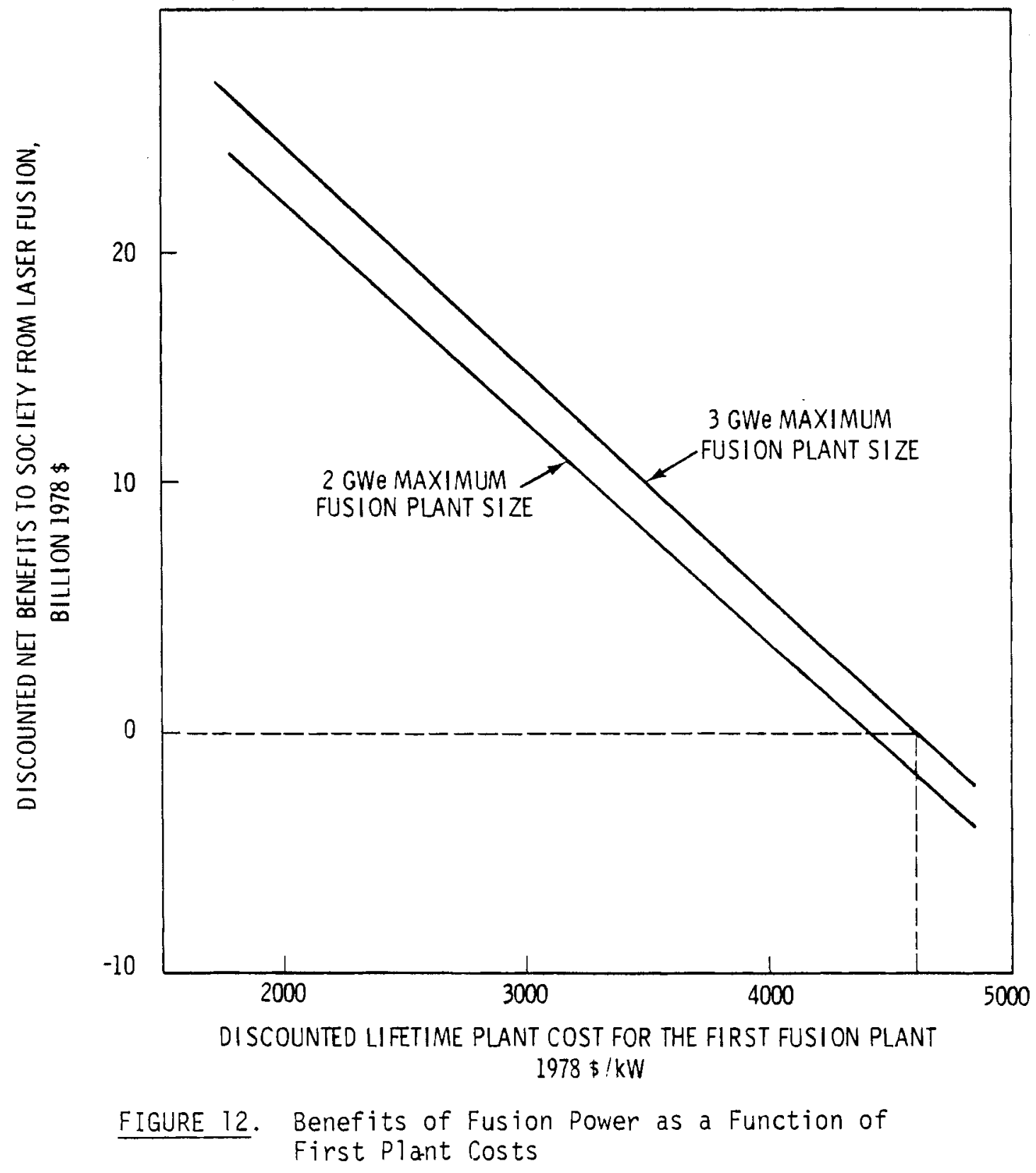


Two lines are drawn, the upper corresponding to a fusion plant size of 3 GWe and the lower to a 2 GWe size. If we examine the cost of the initial plant which corresponds to a zero level of net benefits to society ( $\$ 4000 / \mathrm{kW}$ assuming 2 GWe plants and $\$ 4600 / \mathrm{kW}$ assuming 3 GWe plants), we see that only if the initial plant costs were to exceed $\$ 4400 / \mathrm{kW}$ would the net benefits be zero. It should be remembered that the cost of the alternative technology plant is assumed to be about $\$ 2300 / \mathrm{kW}$ at the time laser fusion enters the commercial market. We are, therefore, talking about zero benefits only if the initial cost of the new technology is more than twice that of the alternative. A reasonable target cost for the first fusion plant would amount to about $\$ 3500 / \mathrm{kW}$. This would yield a net benefit of $\$ 10$ billion and a benefit-cost ratio of about 3 , assuming the fusion program were to cost $\$ 10$ billion.

\section{SENSITIVITY OF RESULTS TO SOME KEY FACTORS}

Finally, the sensitivity of the results of our analysis to changes in some of the parameter values has been examined. Table 2 presents the results comparabie to those in Figure 12 for specified changes in the indicated parameters. The base case in Table 2 corresponds to initial plants costs assumed to be $\$ 3000 / \mathrm{kW}$. Other cases correspond to 1) $4.5 \%$ annual electric demand growth, 2) a 50\% increasing in learning, 3) a 100\% increase in transmission

TABLE 2. Discounted Net Benefits to Society for Various Mini-Model Parameters with First Laser Fusion Plant Cost at $\$ 3000 / \mathrm{kW}$ (Billions of 1978 Dollars)

\begin{tabular}{|c|c|c|c|c|c|c|c|}
\hline $\begin{array}{c}\text { Maximum } \\
\text { Plant Capacity } \\
\text { (GWe) } \\
\end{array}$ & $\begin{array}{c}\text { Base Case } \\
3.5 \% \\
\text { Growth Rate } \\
\end{array}$ & $\begin{array}{l}4.5 \% \\
\text { Growth Rate } \\
\end{array}$ & $\begin{array}{l}50 \% \text { Increase } \\
\text { Learning Coeff. }\end{array}$ & $\begin{array}{l}100 \% \text { Increase In } \\
\text { Transmission cost }\end{array}$ & $\begin{array}{l}20 \% \text { Decrease In } \\
\text { Economy-of-5cale }\end{array}$ & $\begin{array}{l}100 \% \text { increase In } \\
\text { Development Cost }\end{array}$ & $\begin{array}{c}5 \% \\
\text { Discount } \\
\text { Rate } \\
\end{array}$ \\
\hline 1 & 3.863 & 8,424 & 9,524 & 5,667 & 5,242 & 5,241 & 48,508 \\
\hline 2 & 11,072 & 23,200 & 18,312 & 12,903 & 10.377 & 12.827 & 104,670 \\
\hline 3 & 13,151 & 31,952 & 20,304 & 14,595 & 10,994 & 14,908 & 117,397 \\
\hline 4 & 12,898 & 33,875 & 19,560 & 14,038 & 10,140 & 14,534 & 115,109 \\
\hline 5 & 12,586 & 33,594 & 19,019 & 13,584 & 9,574 & 14,153 & 111,915 \\
\hline 5 & 12,381 & 33,356 & 18,722 & 13,315 & 9,255 & 13,911 & 109,552 \\
\hline
\end{tabular}


costs, 4) a $20 \%$ increase in economies of scale, 5) a $100 \%$ increase in development costs, and 6) $5 \%$ discount rate. The stability of the optimal plant size can be clearly seen from the boxes placed around the maximum benefit entry for each parameter and Table 2. For each of the parameters, the net benefits to society varied from $\$ 11$ to $\$ 117$ billion demonstrating the sensitivity of each parameter to the outcome. In al1 but the last case, the change in parameter has a direct change in the cost/benefit ratio. However, in the case where a $5 \%$ discount rate is applied, this discount rate must also be applied to the expenditure side in the cost/benefit calculation. 


\subsection{SUGGESTIONS FOR FURTHER WORK}

The sensitivity of the simulation results to variations in some of the assumptions made has been examined to a limited extent. A sensitivity analysis should be conducted more systematically for these assumptions. The sensitivity of the results to variations in each of the other basic assumptions also needs to be systematically explored.

We have chosen a $10 \%$ discount rate. Alternative discount rates such as $5 \%, 8 \%$ and $12 \%$ should be specified. The pattern of market penetration has been assumed; alternative rules for penetration should be examined. Moreover, we assume the maximum penetration to be $40 \%$ of new base load construction; alternative penetration from $40 \%$ to $50 \%$ should be considered. The length of the construction period has been specified to be a function of the size of the plant. Alternative values for the parameters of this relation should be assessed. The distribution of utility systems according to their size has been assumed to be the same as in the past; alternative assumptions for the distribution should be made. We assume the consortium size to be 4 times the nominal system size; consortium sizes equal to twice the nominal size and 6 times the nominal size should be specified.

We have assumed that there will be scale economies in the construction of laser fusion plants similar to those experienced in the past for more conventional plants. Although we have examined the sensitivity of the results to variation in the value of the scaling parameter, we have not examined the possibility that there will not be increasing returns to scale. The cases of constant returns to scale (in which average costs remain constant for larger plants) and decreasing returns to scale (in which average costs increase for larger plants) should also be examined. 



\subsection{REFERENCES}

1. D. E. Deonigi and R. L. Engel, Laser-Fusion Hybird in Future Electrical Generating Systems. Pacific Northwest Laboratory, Richland, WA. 99352, rough draft, March 1977.

2. D. J. Drayfuss, B. W. Augenstein, W. E. Mooz, and P. A. Sher, An Examination of Alternative Nuclear Breeding Methods. R-2267-D0E, Rand Corp. Santa Monica, CA. 90406, July 1978.

3. Final Environmental Statement. Liquid Metal Fast Breeder Reactor Program. Vol. 1 of 3 Vol., ERDA-1535, U. S. Energy Research \& Development Admin., Wash., D. C. 20545, December 1975.

4. D. E. Deonigi and R. L. Engel, Performance Targets for Fusion-Fission (Hybrid Reactors. BNWL-2139, Pacific Northwest Laboratory, Richland, WA 99352, January 1977.

5. Proceedings of the Second Fusion-Fission Energy Systems Review Meeting. Vol. II. CONF-771155, U. S. Department of Energy, Assistant Secretary for Energy Technology, Office of Fusion Energy, Wash., D. C. 20545, July 1978.

6. Nuclear Energy Center Site Survey - 1975. NUREG-0001-ES, Executive Summary, U. S. Nuclear Regulatory Commission, Washington DC, January 1976.

7. R. Nanda and G. L. Adler, Learning Curves Theory and Application. AIIE-WM\&ME-77-6, Publication No. 6 in the monograph series, Work Measurement and Methods Engineering Division. American Institute of Industrial Engineers, Inc.

8. P. F. Ostwald and J. B. Reisdorf, Measurement of Technology Progress and Capital Cost for Nuclear, Coal-Fired, and Gas-Fired Power Plants Using the Learning Curve. College of Engineering and Applied Science, University of Colorado, Boulder, CO., and Stearns-Roger, Inc., Denver, CO.

9. W. H. Comotors, "Economy of Scale in Power Plants". Power Engineering, 81(8), August 1978.

10. Laser Fusion Hybird Reactor Systems Study. Bechtel Corporation, for Lawrence Livermore Laboratory, July 1976.

11. W. D. Marsh, et a 1., Perspectives on the Design and Application of Generation Planning Programs. The General Electric Co., 1973.

12. R. L. Richardson, Regional Analysis of the U.S. Electric Power Industry. Vol. 6. Transmission Cost Analysis. BNWL-B-415-V6, Pacific Northwest Laboratory, Richland, WA 99352, Apri1 1975. 


\section{REFERENCES (Continued)}

13. W. Allen, Nuclear Reactors for Generating Electricity: U. S. Development From 1946 to 1963. R-2116-NSF, Rand Corp., Santa Monica, CA. 90406, June 1977.

14. R. Perry, et al., Development and Commercialization of the Light Water Reactor, 1946-1976. R-2180-NSF, Rand Corp., Santa Monica, CA. 90406, June 1977.

15. Jackson \& Moreland and S. M. Stoller Associates, Current Status and Future Technical \& Economic Potential of Light Water Reactors. WASH-1082, Prepared for Division of Reactor Development \& Technology, U. S. Atomic Energy Commission, Washington, D. C., March 1968.

16. Utility Requirements for Fusion Power. EPRI-ER-452, Electric Power Research Institute, Palo Alto, CA., May 1977.

17. T. L. Willke, et al., Engineering Development Program Plan for Inertial Confinement Fusion. Vol. II . Program Strategy. PNL-2582, Battelle, Pacific Northwest Laboratories, Richland, WA, March 1978.

18. T. L. Willke, "A Plan for the Development and Commercialization of Inertial Confinement Fusion." Presented to The Heavy Ion Fusion Conference, Argonne National Laboratory, Chicago, I1linois, September 21, 1978. 


\section{APPENDIX A}

The following calculational method allows determination of scale economies when there are varying component economies of scale.

Let:

$$
\begin{aligned}
S_{A} & =\text { size of Plant } A \\
S_{B} & =\text { size of Plant } B \\
C_{A} & =\cos t \text { of Plant } A \\
C_{B} & =\operatorname{cost} \text { of Plant } B \\
C_{i A} & =\text { cost of component } i \text {, Plant } A \\
C_{i B} & =\text { cost of component } i \text {, Plant } B \\
C_{A} & =\text { per unit cost, Plant } A \\
C_{B} & =\text { per unit cost, Plant } B \\
g_{i} & =\text { share of component } i \text { in total cost } \\
P_{i} & =\text { exponential scaling parameter for component } i .
\end{aligned}
$$

By definition:

$$
c_{i A}=g_{i} C_{A} \text { and } c_{i A}=c_{i B}\left(\frac{S_{A}}{S_{B}}\right)^{P_{i}}
$$

However, $\quad \bar{C}_{A}=\frac{C_{A}}{S_{A}}, \quad \bar{C}_{B}=\frac{C_{B}}{S_{B}}$

Then

$$
\frac{C_{A}}{\bar{C}_{B}}=\frac{\frac{C_{A}}{S_{A}}}{\frac{C_{B}}{S_{B}}}=\frac{C_{A}}{C_{B}} \cdot \frac{S_{B}}{S_{A}}
$$

But

$$
c_{A}=\sum_{1}^{6} \quad c_{i A}=\sum_{1}^{6} c_{i B}\left(\frac{S_{A}}{S_{B}}\right)^{P_{i}}
$$


So

$$
\frac{\bar{C}_{A}}{\bar{C}_{B}}=\frac{1}{C_{B}}\left(\frac{S_{B}}{S_{A}}\right) \sum_{i}^{6} C_{i B}\left(\frac{S_{A}}{S_{B}}\right)^{P}
$$

Combining terms in the summation:

$$
\begin{aligned}
& \bar{c}_{A}=\sum_{i=1}^{6} c_{i B}\left(\frac{S_{A}}{S_{B}}\right)^{P_{i}} \cdot \frac{1}{S_{A}} \\
& \bar{C}_{A}=\sum_{1}^{6} c_{i B}\left(\frac{S_{A}}{S_{B}}\right)^{\frac{P_{i}-1}{P_{i}}}
\end{aligned}
$$


PNL-2803

UC-20d

\section{DISTRIBUTION}

No. of

Copies

OFFSITE

A. A. Churm

DOE Patent Division 9800 S. Cass Avenue

Argonne, IL 60439

139 DOE Technical Information Center

C. Head

DOE Office of Fusion Energy Washington, DC 20545

R. Kostoff

DOE Office of Fusion Energy Washington, DC 20545

E. Rossi

DOE Office of Laser Fusion Washington, DC 20545

N. Amherd

Electric Power Research Institute

3412 Hillview Avenue

Palo Al to, CA 94304

W. C. Wolkenhauer

Washington Public Power Supply System

3000 George Washington Way

Richland, WA 99352

\section{ONSITE}

DOE Richland Operations

H. E. Ransom
No. of

Copies

45 Pacific Northwest Laboratory

JB Burnham

DE Deonigi

DA Dingee (10)

DW Fraley

RC Liikala

AD Rockwood

SC Schulte

VL Teofilo

LD Williams

TL Willke

Economics Library (20)

Technical Information Files (5)

Publishing Coordination 
.
.
. 